\title{
Advanced Solar Operated Multi Purpose Agricultural Equipment
}

\author{
Chandana N C, Chethan Kumar V U, Mahadevaprasad G B, Shiva Kumar M
}

\begin{abstract}
In today's aggressive world there may be a need for a quicker rate of production in agriculture. As we recognize Agriculture is the backbone of India. In India nearly all farmers dealing with issues of a exertions shortage. Day with the aid of using day exertions wages is increasing. In India, the Cotton crop is cultivated in a big amount. After yielding of cotton, the principle trouble face with the aid of using the farmers is to reduce the cotton stalk. Nowadays what farmer did is pluck the cotton stalk manually gather at one place, wait until the stalk receives dry, and after that burn that crop. The downside of burning the crop is, the vitamins which can be released after burning are typically washed away. Soil declines in productiveness after burning. Crop residues last withinside the discipline after the harvest are eliminated with the aid of using burning the stubble or leaving the stalks on the sphere surface, to be mixed with soil both without delay or with the aid of using mechanized chopping. So our purpose is to design and fabrication of the sort of system that can reduce and overwhelmed of cotton stalk. After crushing the overwhelmed crop unfold at the farm. So that this overwhelmed crop is dumped into the soil and it used as natural compost. So the productiveness of soil could be increased, .
\end{abstract}

Keywords: Ploughing, digging, seed sowing, fertilizer pouring, weeding

\section{INTRODUCTION}

One of the most vital activity in agriculture India is the want to discover and implement new thoughts on this field, even though there is lots of labor to be finished on this area. It has been cited that those thoughts aren't nicely applied withinside the actual agriculture region. This is because of the excessive price and the skillful for rural people. Multipurpose agricultural implements are the simple and maximum vital gear in agriculture for max yield. The conventional technique of planting and cultivating sugarcane is an laborious technique and because of this there may be a scarcity of labor, delaying agriculture to triumph over those difficulties, designed multipurpose farming equipment. Agriculture performs an vital position in the Indian economy. $70 \%$ of rural families depend upon agriculture. Agriculture is a primary region of the Indian economy, contributing approximately $8.4 \%$ of general GDP and using extra than $60 \%$ of the population. Indian agriculture has been fluent withinside the previous couple of decades. The records of agriculture in India dates lower back to the generation of Indus Valley civilization.

Manuscript received on January 27, 2021

Revised Manuscript received on February 22, 2021

Manuscript published on February 28, 2021

Chandana N C, Department of Mechanical Engineering DBIT, Bangalore - 560074

Chethan Kumar V U, Department of Mechanical Engineering DBIT, Bangalore - 560074

Mahadevaprasad G B, Department of Mechanical Engineering DBIT, Bangalore - 560074

Shiva Kumar M, Department of Mechanical Engineering DBIT, Bangalore - 560074
Today, India ranks $2^{\text {nd }}$ withinside the international in agricultural production. Specialty vehicles play an critical function in numerous sectors which includes industrial, medical, and army applications, even as the specialised automotive zone is gradually growing its productiveness in agriculture. Some of the important issues in Indian agriculture is the rise in the expenses and the supply of skilled labour . To overcome over such adversity, automation technology have been used in agriculture. Automation in agriculture allows farmers lessen their efforts. Vehicles are being evolved for ploughing, seed sowing, levelling, and welding processes. All these duties have now no longer but been executed the use of the equal automobile. It is evolved to recognition on robots successfully and is anticipated to carry out operations autonomously. The proposed concept is to put in force the automobile to carry out duties which includes ploughing, sowing, soil levelling, weeding. These duties may be mixed into one automobile after which executed

\section{LITERATURE SURVEY}

Since last century, mechanization is continuously adapted in agriculture. Various developments in farm machineries have been observed. The machineries with high costs and with low costs are available. The approach toward various multipurpose, handy equipment is also seen. Affordable and easy to use machines have been developed.

1. D.A. Mada, Mahai : In this research paper, the writer cites the size of automation in agriculture by giving a few examples. The end of the paper became that a multifunctional vehicle became required for pre and postharvest. We have taken this because of the basis of our studies and feature took high-quality

modifications in our multipurpose manufacturing farm vehicle.

2. V.K. Tewari, : In those research papers, the authors have completed a case examine on agricultural automation in West Bengal, that's a part of India, which offers a clean function on availability and development in India. This ensured us to take corrective measures as compared to present day levels.

3. F.A. Adamu,: The author on this paper draws our interest to the overall performance thing of the Power Tiller. The call for a low-weight electric- powered tiller became a lot sought after. Such parameters as strong performance and subject potential also are discussed. We have taken into consideration the one's elements whilst designing a sustainable multifunctional farm vehicle.

Published By:

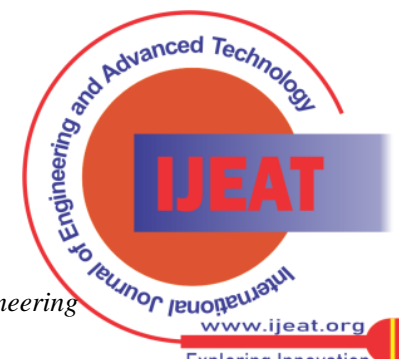




\section{Advanced Solar Operated Multi Purpose Agricultural Equipment}

4. P. Raman et al : This paper describes the improvement of the solar inert system, which affords thermal consolation at some point of the year in combined climates. In the primary step, a passive version one comprising units of solar chimneys according to 1 calendar year is advanced and monitored for its performance.

\section{WORKING PRINCIPLE}

India is the country wherein agriculture is the principle career and subculture and the cause at the back of that is that maximum farmers in India are suicidal due to the fact $10-20 \%$ of the farmers in India are rich however the relaxation of the farmers don't have any supply to purchase heavy system and machinery. So we determined to layout an agricultural automobile that might meet the fundamental wishes of agriculture and the cost of a farm vehicle need to be very low as compared to different farm vehicles. The fundamental reason of a farm vehicle is digging, plowing, sowing, and weeding

We designed this kind of farm automobile to cope with the following purpose

- When the motor is began out the wheel starts to operation. The sowing operation may be finished semiguide.

- $\quad$ Easily mounting and fastening the ploughing tool, this operation is finished through manual force.

\section{DIMENSION OF THE PARTS}

\begin{tabular}{|l|l|}
\hline Wheel diameter & $350 \mathrm{~mm}$ \\
\hline Frame diameter & $35 \mathrm{~mm}$ \\
\hline Length & $880 \mathrm{~mm}$ \\
\hline Width & $50 \mathrm{~mm}$ \\
\hline Light diameter & $60 \mathrm{~mm}$ \\
\hline Stand diameter & $60 \mathrm{~mm}$ \\
\hline
\end{tabular}

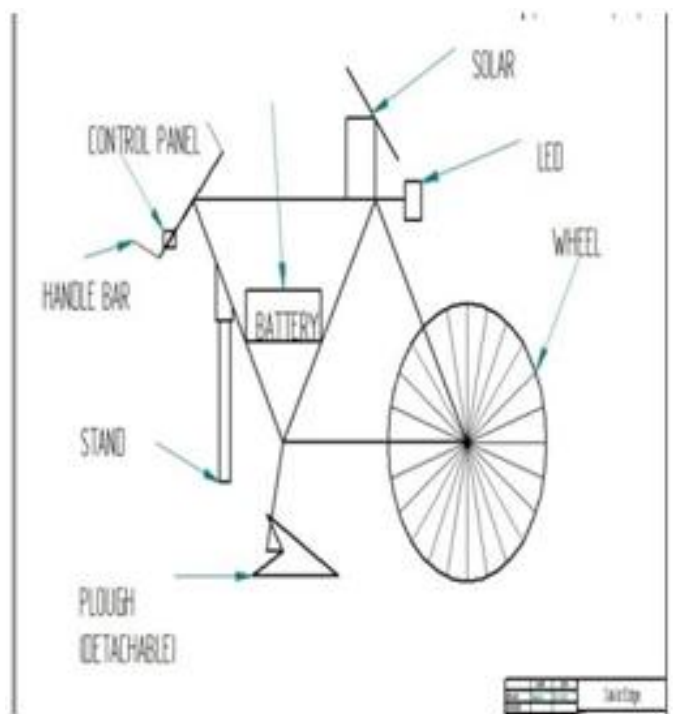

Fig.3.1 Concept diagram Multipurpose agriculture Vehicle rotate the excavator, finishing the paving and weeding

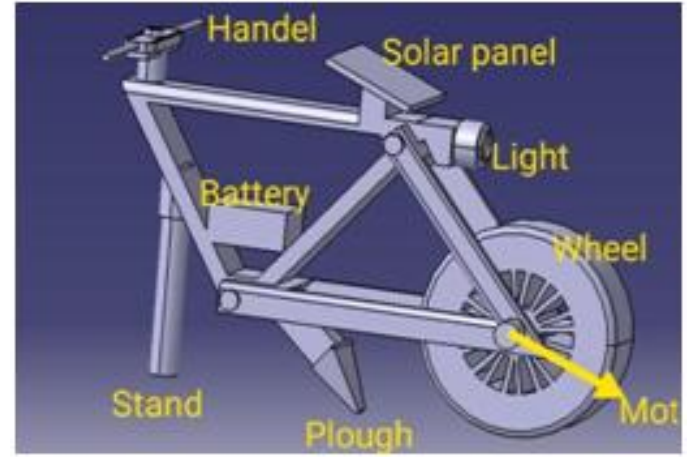

Fig3.2 (a)

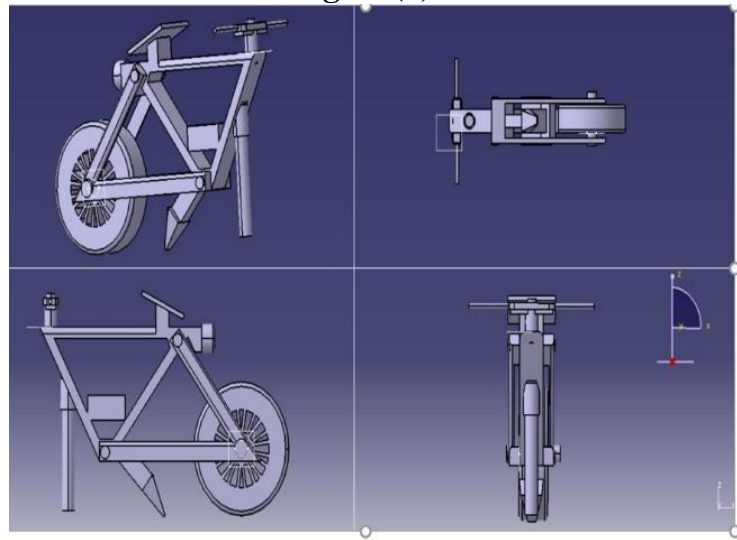

Fig3.2 (b)

Fig.3.2 Final Design of the Proposed Model transformed into electric strength that is saved in battery and the battery is used for the sowing, digging and different agricultural process. The panel is constant to the body and the panel is hooked up to the battery and it is hooked up to the switches and the separate DC motors have separate switches to manipulate and additionally the spraying of water is likewise controlled. The distinct Dc motors are used to manipulate the motion and different processes

\subsection{Weeding}

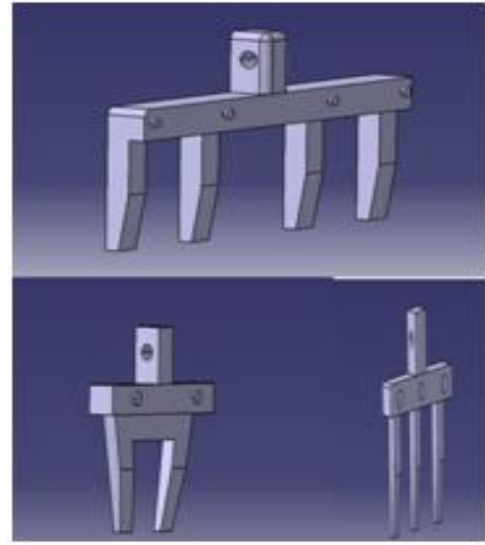

Fig.4.2 Weeder

A set of vitamins. It facilitates in lowering soil erosion. Weeding is the manner of getting rid of weed from the field. Weeding is the vital step in agriculture due to weeds aren't removed, they'll eat vitamins from the plants. It is performed in order that the soil of framers isn't always used for simplest one.

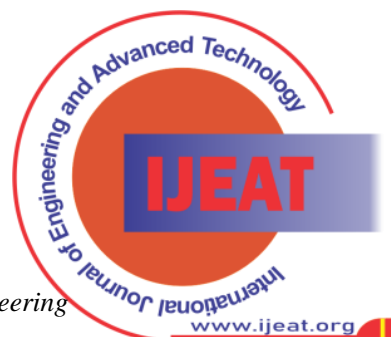




\section{COMPONENTS OF SYSTEM}

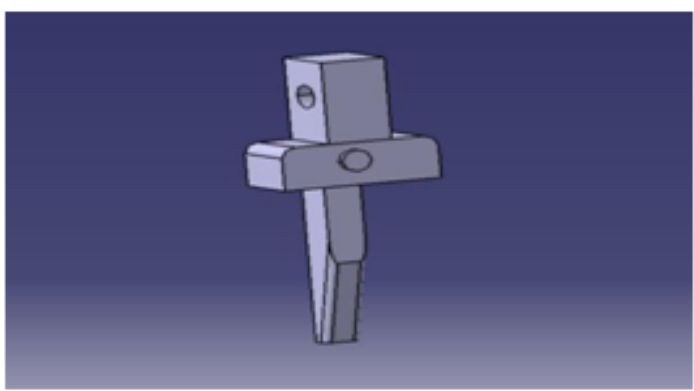

Figure 4.1 Ploughing

\section{Levelling}

3 Leveller

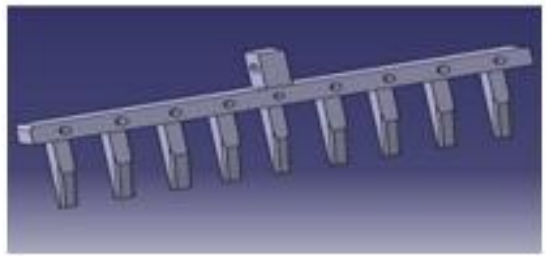

Figure 4.1 Plougher

The number one reason of ploughing is to turn over the top layer of the soil, bringing clean vitamins to the surface, while burying weeds and the stays of preceding vegetation and letting them breakdown. As the plow is drawn through pressure withinside the form of torque implemented on the

\section{Solar Panel}

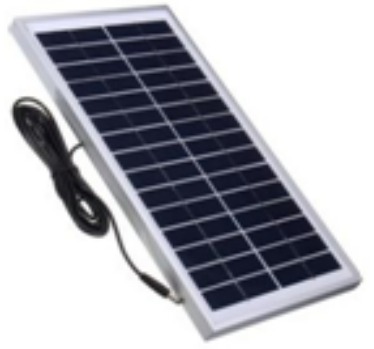

Fig.4.5 Solar Panel

The term solar panel is used colloquially for a photo-voltaic module. A PV module is an assembly of photovoltaic cells hooked up in a frame work for installation. Photo-voltaic cells use daylight as a supply of power and generate direct contemporary electricity.

\section{Battery}

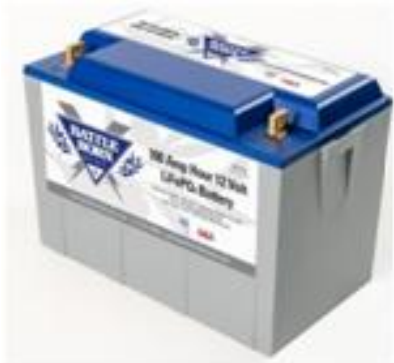

Fig.4.6 Battery

A battery is an the electrochemical cell (or enclosed and guarded material) that may be charged electrically to offer a static ability for electricity or launched electrical charge when needed. motor's shaft.

the soil it creates lengthy trenches of fertile soil known as furrows. In modern use, a ploughed area is usually left to dry out and is then harrowed earlier than planting. Ploughing and cultivating a soil homogenizes and modifies the top 12 to $25 \mathrm{~cm}$ of the soil to shape a plough layer. In many soils, the bulk of quality plant feeder roots can be discovered withinside the topsoil or plough layer. A Sheetmetal Plate is used as mud closer and leveler, The lengthy bolt and nut is used for leveler up \& down movement. The Leveler isn't always powered, as an alternative it is constant to the desired degree initially, The leveler closes the soil withinside the sowed soil and degrees the land.

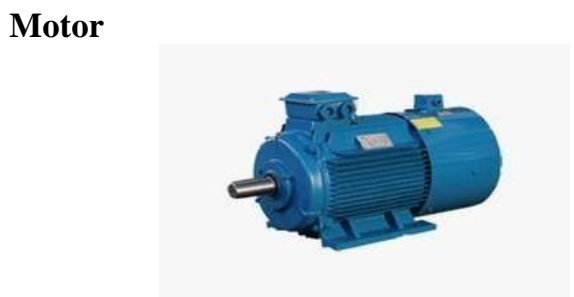

Fig.4.4 Motor

An electric powered motor is an electrical system that converts electrical energy into mechanical electricity. Most electric-powered motors function via the interplay among the motor's magnetic field and electric powered cuttingedge in a twine winding to generate

\section{FEATURES OF VEHICLE}

- Multipurpose, can carry out cultivations operations consisting of ploughing, cloud breaking, sowing, fertilizing, levelling, weeding, weedicide application.

- Multitasking, in a single assembly of the equipment, it plays sowing, fertilizing, and leveling. In every other assembly, it performs weeding and weedicide application.

- Automated, the equipment may be animal-powered or tractor powered simply pulling off the gadget is sufficient and the rest of the moves are automated.

- The Successful enforce of clinical farming with our gadget will cause better yield and higher first-rate of crop.

- The number of people required is decreased excessively, which in flip reduces labor charges.

- Variable with dimensions and farming specifications

- Adopted scientific farming and Precision forming technology.

- Our equipment is completely flexible for smooth assembly and disassembly

\section{SCOPE FOR FUTURE WORK}

By increasing the device power and first- class to its peak, we will have multipurpose agricultural device for lifetime usage. By imparting solar panels, Battery, and a few minor modifications to the device.

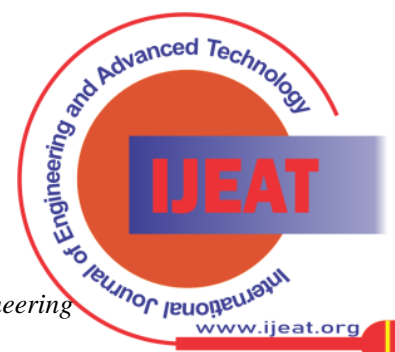




\section{Advanced Solar Operated Multi Purpose Agricultural Equipment}

\section{CONCLUSION}

Practically our multipurpose agricultural instrumentality will be used for cultivation, fertilizing, digging, levelling, and additionally used for weed removal functions. All the elements are connected in such a way that in each stage of agriculture the instrumentality can be rearranged or simply assembled with fasteners to needed length and specifications of field operation. Our team has with success combined several concepts from varied fields of engineering science and agricultural data to improve the yield and by reducing the labour effort and expenses. The total plan could be a new concept and might be with success enforced in real-life situations.

\section{REFERENCES}

1. R. Sadiq, S. Gopala Krishna ,"Design and fabrication of multipurpose agricultural equipment", International Journal of Advances in Production and Mechanical Engineering,1,(2015),3845.[1]

2. Kannan, K. Esakki raja, "Design modifications in multipurpose sowing machine", International Journal of Research in Aeronautical and MechanicalEngineering,2,(2014),35-40.[2]

3. D. Ramesh, H. Girish kumar,"Agriculture seed sowing equipments : A review international journal of science", Engineering and Technology, (2014) 1987- 1992. [3]

4. T. Sambouli, N. Zapata, "Performance of new agricultural impact sprinkler fitted with plastic nozzles", Biosystems Engineering,118,(2014),39- 51.[4]

5. P. Vijay, K. Rakesh, "Design of a multi- purpose seed sower cum plougher", International Journal of Emerging Technology and Advanced Engineering,3,(2013),1-8.[5]

6. K. Hao, z. Ripin, "Nodal control of grass trimmer handle vibration", International Journal of Industrial Ergonomics,43,(2013),18-30.[6]

7. Girish, S. Satyavrath, "Design and fabrication of multipurpose farm equipment".[7] 